\title{
A Markedness Differential Approach Towards the Acquisition of English Locative Inversion for Chinese L2 Learners
}

\author{
Luyi Song ${ }^{1 *}$ \\ ${ }^{1}$ Shanghai International Studies University, Shanghai 200083, China \\ *Corresponding author. Email: 0151160011@ shisu.edu.cn
}

\begin{abstract}
The research is an exploration of Chinese ESL learners using locative inversion from the perspective of "markedness". The participants were demanded to translate sentences in Chinese to English, all of which can be translated to either sentences using locative inversion or canonical order. The results show that Chinese learners can use locative inversion correctly and more often, which is contrary to the prediction of Markedness Differential Hypothesis that the more marked structure in target language will be difficult to learn. It is due to the influence of Chinese, which makes it easy for them to understand and use locative inversion in English. However, it is still necessary to master specific grammar rules in order to use it properly. The paper suggests that an unmarked feature in L1 can transfer to L2, though it is marked in L2. However, to fully master the structure in L2 requires efforts.
\end{abstract}

Keywords: locative inversion, markedness, English learners.

\section{INTRODUCTION}

English is the most general and widely studied foreign language in China. The number of people learning it and the years invested outweigh any other foreign language. It is taught as a compulsory subject and tested in senior high school and college entrance examinations, hence most Chinese students start learning English from a very young age, usually from primary school. However, the current situation is that even though Chinese learners spend much time and effort studying English, it is still a challenge for them to master the language. On one hand, according to Shi \& Liu, students are not interested in English and hold a negative view towards English learning [1]. On the other hand, English and Chinese differ in many aspects, for example, in pronunciation, spelling, and grammar. Therefore, it is understandable that students confront great difficulty when studying its grammar and grammar mistakes are evident in their output.

The paper is focused on locative inversion, which is used differently in two languages and students make many mistakes. For example, "Here comes the car" in English and "lai2 che1 le" in Chinese. However, the structure of locative inversion in English can be diversified and not as simple as the given example.
Therefore, Chinese learners who are acquiring English as L2 often find it difficult to use locative inversion correctly when they are speaking English. For some, it does not seem to matter as long as their expressions, no matter in what ordering, can be understood by other people. However, under certain circumstances it is necessary to use locative inversion, especially when people want to focus or emphasize on something, whether in spoken or written language. Thus, there is need to learn and use it properly. At the same time, it is worth studying what causes the confusion and what can be done to help students to acquire the structure more easily and firmly.

As a way to stress the place in a sentence, locative inversion can be regarded as "marked" with respect to the word order. Eckman defines "markedness" as "a phenomenon $\mathrm{A}$ in some language is more marked than $\mathrm{B}$ if the presence of $\mathrm{A}$ in a language implies the presence of B; but the presence of B does not imply the presence of A" [2]. According to Salzmann, although locative inversion is a prominent construction in Bantu languages, it is relatively more rarely described in other languages, including English and Chinese [3]. This rarity suggests that locative inversion should be considered as a marked feature in English and Chinese. 
Based on different versions of definition, it can be inferred that locative inversion, which requires moving the locative indicator to the beginning of the sentence and then switching the position of the subject and the verb, should be considered more marked than the canonical order. That is to say, "Here comes the car" is more marked than "Here comes the car" and "lai2 che1 le" is more marked than "che1 lai2 le".

In the paper mentioned in the previous paragraph, Eckman also puts forward the Markedness Differential Hypothesis (MDH), which suggests that some areas in L2 will be harder to learn if they are more marked than in L1 and the degree of difficulty depends on the degree of "markedness" [2]. That is to say, the more marked a structure is, the harder it will be to learn. Different scholars have done research to test its applicability. For example, Eckman does research on the usage of relative clause and the respondents who received a lesson on relative clause focused on the object of a preposition improved most on the test in which they were required to combine two sentences into one using a relative clause because it is the most marked structure in relative clause and the respondents were supposed to automatically generalize its usage [4]. Chaudron \& Parker proves that when Japanese learners of English were studying noun phrases, they first acquired the least marked structural forms and then moved on to the more marked ones, and the use of structurally more marked phrases occur more frequently as they progress in English [5]. AL-Makatrah et al. demonstrates that Arabic learners make more mistakes on do-support than $\mathrm{BE}$ and HAVE because do-support is more marked and thus more difficult to master, even though the advanced learners who seem to master these three auxiliaries commit the most errors in regard to the usage of dosupport [6]. Li studies Chinese students' usage of relative clause and reveals that they would avoid using more marked types [7]. Wang \& Wu research on the usage of tense by Chinese learners and concludes that students make more mistakes with respect to irregular verbs than regular verbs, since irregular verbs are more marked. They also concludes that students make more errors on composite past tense than past tense [8]. Mehrdad \& Ahghar has researched on "markedness" and syllabus design and found out that MDH's applications to syllabus design have not been generalized because the relationship between "markedness" and difficulty is still in doubt [9].

In short, "markedness", in contrast to "unmarkedness" in target language, is harder to acquire. Chinese and English both are SVO order, so locative inversion, as a marked form in English syntax, will be more difficult to learn than normal word order, which can explain why students often make mistakes when using locative inversion. Nevertheless, the results found from 48 respondents is that more students choose to use sentences in locative inversion, not normal order, to translate the sentences in Chinese. The results show that students do not have difficulty in using locative inversion. Rather, they show a tendency to use locative inversion, which is contradictory to what the $\mathrm{MDH}$ predicts.

Based on the above mentioned literature, there is little research on the "markedness" of locative inversion, nor is it clear how it affects the performance of Chinese L2 learners. Therefore, this paper has studied usage patterns of Chinese students by means of questionnaire, with the purpose of presenting the situation of "markedness" influence on L2 acquisition of locative inversion.

Therefore, this paper will first give the methodology used in the questionnaire, and then focus on the seemingly contradictory results and try to argument whether MDH can be applied to locative inversion. At last, this paper will find out whether MDH is equivalent to the degree of difficulty and analyze how "markedness" influence the process of SLA as well as give some suggestions on locative inversion learning and teaching to students and teachers.

\section{METHODS}

\subsection{Questionnaire survey}

The data used in the research are obtained from an online questionnaire survey I devised. The respondents are all Chinese students who have learned English for different periods of time, ranging from one year to more than ten years. The questionnaire contains two parts. In the first part, there are 4 sentences in Chinese and they are translated into English. All choices are presented with the same words, but in different orders, some are correct while others are wrong. The respondents are required to choose the answer(s) they think is/are correct. If the respondents think that none is correct, they can give their own answer. The second part is about respondents' basic information, including gender, age, educational background, years they have spent studying English, whether they have studied inversion before and what they think is difficult about inversion.

Altogether, 48 people answered the questionnaire, 14 male and 34 female. All of the study participants' age ranges from under 18 to 45 -year-old. 23 people are aged under 18,20 between 18 and 25-year-old, 4 between 25 to 35-year-old and one above 35-year-old. 24 people have studied English for more than ten years, accounting for $50 \%$ of all participants, 15 people for 6 10 years, 8 for 3-6 years and one for less than 3 years. The respondents' diploma or currently attending school level are quite diverse. There is one person in junior school, 23 in senior school, 2 in junior college, 11 in university, 10 in master and one in doctor. Only 2 people said that they had not learned inversion. 17 
people had learned inversion and still remembered, while 29 had forgotten about the specific content.

The data are appropriate for answering the research question because $96 \%$ of the respondents stated that they had learned inversion before, though, in which $60 \%$ said that they had forgotten. Nevertheless, it is meaningful to study their responses and find out why some answers seem to contradict with $\mathrm{MDH}$.

\section{RESULTS AND DISCUSSION}

Statistics from four locative inversion questions produce two distinct results. The participants are required to choose one or more answers that they think can properly translate the sentences in Chinese (canonical word order) to English. If there is no correct answer available, they can give their own version. The tables are shown below.

Based on statistics, we can conclude that besides Q2, Q1, Q3 and Q4 provide unexpected results: more students have chosen the inversion answer rather than sentence in normal order. On the contrary, MDH predicts that students should use normal word order more frequently, because it is less marked than inversion. In other words, more students should choose A1.5 than A1.4, A2.2 than A2.1, A3.3 than A3.1 and A4.3 than A4.4. However, in Q1, Q3 and Q4, the statistics show an opposite fact, which is worth answering why.

As stated before in section 1, Saville-Troike interprets "markedness" as a feature that occurs more frequently than another element in the same category, and indicates that it can apply to different levels of linguistic analysis, including phonology, vocabulary, syntax and discourse [10]. In Chinese, unlike English, words or phrases which indicate the location can serve as the subject of the sentence and appear in the beginning of the sentences, as shown in Q1, Q3 and Q4: lai2 "comes here", chu1xi2le hui4yi4 "were present at the meeting", jiao4tang2 fu4jin4 "near the church" in Q1, Q3 and Q4. Therefore, the three sentences can be spoken in two ways: one with the noun as the subject and the other with the locative indicator as the subject. There are more examples given by Zhang [11]:

$\begin{array}{lllll}\text { Kao4qiang2 } & \text { shi4 } & \text { yi1 } & \text { pai2 } & \text { shu1jia4 } \\ \text { against the wall is } & \text { one } & \text { CLF } & \text { bookshelf }\end{array}$

As concluded by Saville-Troike, unmarked feature in L1 can transfer to L2, though in L2 it is a marked feature [10]. The unmarkedness of locative inversion in Chinese outweighs its marked standing in English, hence locative inversion is regarded as normal for Chinese students. A1.4, A3.1 and A4.4 are chosen by the most people respectively. The three answers, which start with locative indicator, are considered as unmarked.
Nevertheless, Q2 renders a seemingly different result from other questions: between the correct answers A2.1 and A2.2, less people choose inversion, which should be considered in accord with the markedness of locative inversion influence. However, based on the analysis in the previous paragraph, sentences with locative inversion in Chinese are unmarked, so they can transfer to English. In this case, "chong1le chu1lai2 "rushed out" can also serve as the subject. Why is it that more people choose "The students rushed out..." rather than "Out rushed the students..."?

The confusion here is caused by the numbers only. Overall, locative inversion answers are chosen most (A2.1, A2.3 and A2.4, 38 in total), compared to the number of sentences in normal word order chosen, regardless of its correctness (A2.2 and A2.4, 33 in total). Hence, the difference here does not violate the principle of unmarkedness of locative inversion in Chinese. The problem is caused by students' inability to produce the right form of locative inversion in English. The conclusion can be testified again by reviewing the results of Q1, Q3 and Q4. Likewise, the same results can be reached in these three questions.

The unmarked characteristic of locative inversion can also be interpreted by the equation by Chinese students of locative inversion with there-be construction, which is remembered as a set structure and used without thinking. In there-be structure, the subject position is occupied by "there", without specific meaning. Likewise, the subject in A1.4, A3.1 and A4.4 can be substituted by "there":

\section{A1.4: Here (There) comes the car.}

A3.1: Present at the meeting (There) were Professor White, Professor Smith and other guests.

\section{A4.4: Near the church (There) was a ruined cottage.}

Because of the naturalness of using there-be construction, students tend to choose the sentences whose locative phrase can be substituted directly by "there".

However, in A2.1 the same substitution cannot be realized: Out (There?) rushed the students the moment the bell rang. The conflict here is that "rush" should be combined with "out" to complete its meaning, so the correct form should be "there rushed out...". If "out" is replaced by "there", the verbal phrase is ungrammatical or at least unnatural. That is why more people choose "The students rushed out...".

To sum up, locative inversion is more marked in English than in Chinese. For Chinese L2 learners, it means that they can transfer locative inversion from L1 to L2 and most of them can use it correctly so long as they have learned the grammar rules in the past. For those who are unable to produce the correct sentences, 
the problem is caused by the inability of exchanging the position of the subject and the verb.

Question 1: How to translate the sentence to English?

$\begin{array}{lll}\text { Che2 lai2 le } & \\ \text { car } & \text { comes } & \text { AUX }\end{array}$

Table 1. Results of Question 1

\begin{tabular}{llll}
\hline Choices & Number of choosing & Percentage & Rate of choosing (N=48) \\
\hline A1.1: Here the car comes. & 13 & $19.4 \%$ & $27.1 \%$ \\
A1.2: The car here comes. & 0 & $0.0 \%$ & $0.0 \%$ \\
A1.3: Here does the car come. & 3 & $4.5 \%$ & $6.3 \%$ \\
A1.4: Here comes the car. & 32 & $47.8 \%$ & $66.7 \%$ \\
A1.5: The car comes here. & 19 & $28.4 \%$ & $39.6 \%$ \\
Total number of choosing & 67 & Average number of choosing & 1.4 \\
\hline
\end{tabular}

Question 2: How to translate the sentence to English?

\begin{tabular}{|c|c|c|}
\hline Ling2sheng1yi1xiang3 & xue2sheng1men jiu4 & chong1 le \\
\hline ell rang & as soon as & AUX \\
\hline
\end{tabular}

Table 2. Results of Question 2

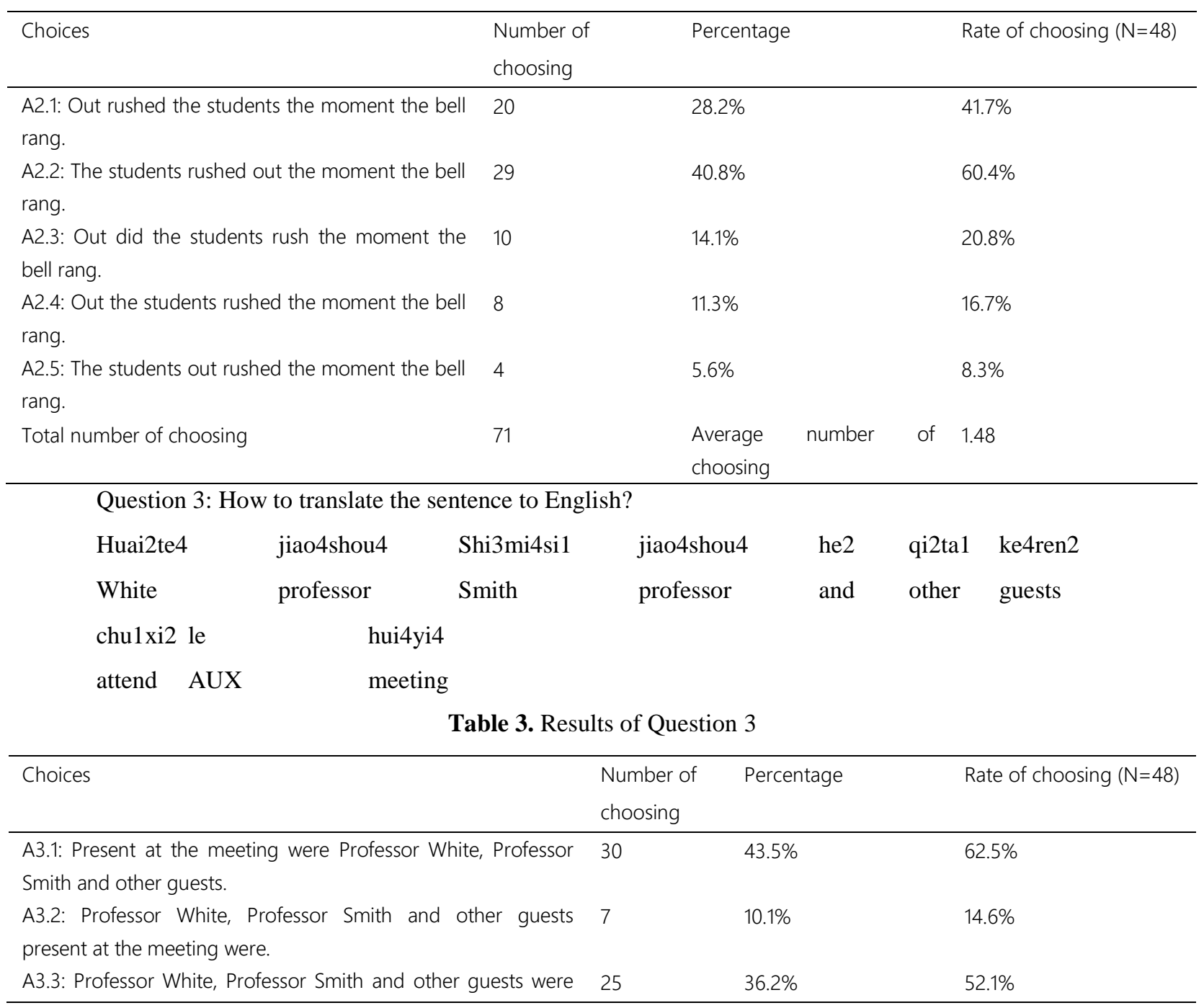




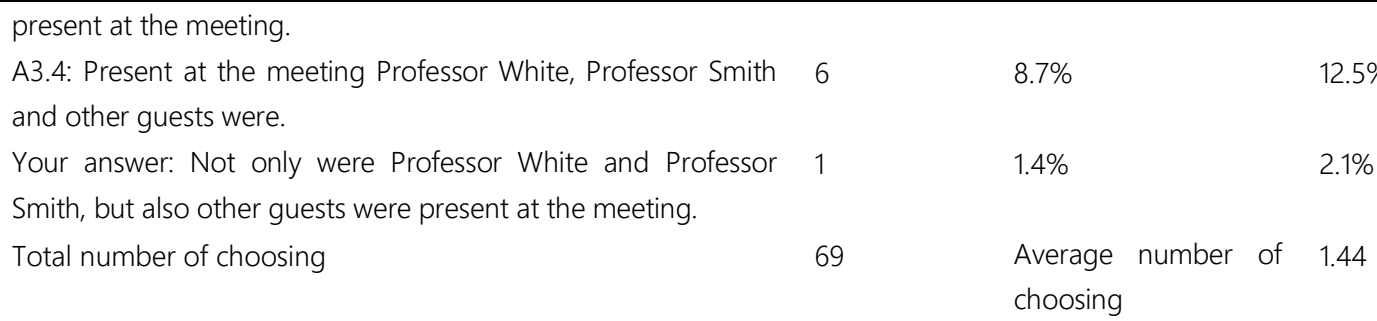

Question 4: How to translate the sentence to English?

$\begin{array}{lllllll}\text { Jiao4tang2 } & \text { fu4jin4 } & \text { you3 } & \text { yi1 } & \text { zhuang4 } & \text { po4jiu4 } & \text { de } \\ \text { the church } & \text { near } & \text { have } & \text { one } & \text { CLF } & \text { ruined } & \text { AUX } \\ \text { xiao3 } & \text { wu1 } & & & & & \\ \text { small } & \text { house } & & & & \end{array}$

Table 4. Results of Question 4

\begin{tabular}{|c|c|c|c|}
\hline Choices & $\begin{array}{l}\text { Number of } \\
\text { choosing }\end{array}$ & Percentage & $\begin{array}{l}\text { Rate of choosing } \\
(\mathrm{N}=48)\end{array}$ \\
\hline A4.1: A ruined cottage near the church was. & 4 & $5.4 \%$ & $8.3 \%$ \\
\hline A4.2: Near the church a ruined cottage was. & 3 & $4.1 \%$ & $6.3 \%$ \\
\hline A4.3: A ruined cottage was near the church. & 30 & $40.5 \%$ & $62.5 \%$ \\
\hline A4.4: Near the church was a ruined cottage. & 37 & $50.0 \%$ & $77.1 \%$ \\
\hline Total number of choosing & 74 & $\begin{array}{l}\text { Average number of } \\
\text { choosing }\end{array}$ & 1.54 \\
\hline
\end{tabular}

Table 5. Overview results of Q1, Q3 and Q4

\begin{tabular}{lll}
\hline Question & $\begin{array}{l}\text { The number of answers in locative inversion } \\
\text { chosen }\end{array}$ & $\begin{array}{l}\text { The number of answers in normal word order } \\
\text { chosen }\end{array}$ \\
\hline Q1 & A1.1, A1.3 and A1.4, 48 in total & A1.2 and A1.5, 19 in total \\
Q3 & A3.1 and A3.4, 36 in total & A3.2 and A3.3, 32 in total \\
Q4 & A4.2 and A4.4, 40 in total & A4.1 and A4.3, 34 in total \\
\hline
\end{tabular}

\section{CONCLUSION}

The aim of the paper is to find out where the difficulty of using locative inversion for Chinese English-learners lies. According to the data collected and analyzed, the fact is that Chinese learners are accustomed to locative inversion and the difficulty lies in other respects. It is demonstrated that locative inversion is unmarked in Chinese. According to MDH, an unmarked feature in L1 can be transferred to L2 though it is a marked feature in L2.

However, it does not mean that it is easy to learn. Based on results analyzed by the research, though Chinese students can use locative inversion, they are prone to make mistakes. For example, whether to add auxiliary verb or to move the verb before the subject. Therefore, though MDH can predict which feature in L2 will be difficult and which will be easy, things get more complicated in real practice. Most grammar patterns involve more than one aspect. For instance, to produce a locative inversion sentence, not only should the locative phrase be moved to the beginning of the sentence, but the verb should also be moved before the subject. Based on the results, it is recommendable that teachers draw more attention to the movement of the verb while teaching, but not locative indicators.

There are some deficiencies in the experimental design. First, there is no comparison in the study between people's performance before and after they are instructed on the related knowledge. Second, the number of respondents is limited, which may influence the results of the survey.

To sum up, the results found in this research show that $\mathrm{MDH}$ can prove that the unmarked feature in L1 can transfer to L2, but whether L2 learners can use the structure in L2 properly requires efforts and study. Therefore, the prediction made by $\mathrm{MDH}$ does not mean that unmarkedness feature transfer is easy to master. 
The theory requires more research before it can be applied to teaching practice.

\section{REFERENCES}

[1] L. Shi, Z. Q. Liu, (2012). A metaphor analysis of learning beliefs among Chinese ESL learners in university, senior high school, junior high school, and elementary school. Journal of Xi'an International Studies University, 20(4), 67-70.

[2] F. R. Eckman, (1977). Markedness and the contrastive analysis hypothesis. Language learning, 27(2), 315-330.

[3] M. Salzmann, (2011). Towards a typology of locative inversion - Bantu, perhaps Chinese and English - but beyond?. Language \& Linguistics Compass, 5(4), 169-189.

[4] F. R. Eckman, (1985). Some theoretical and pedagogical implications of the markedness differential hypothesis. Studies in Second Language Acquisition, 7(3), 289-307.

[5] C. Chaudron, K. Parker, (1990). Discourse markedness and structural markedness: the acquisition of English noun phrases. Studies in Second Language Acquisition, 12(1), 43-64.

[6] E. S. Al-Makatrah, M. S. M. Yasin, M. Z. Sulaiman, M. I. Al-Khawaldeh, (2017). The Markedness in Acquiring Do-support in Negation and Inversion by Adult Native-Arabic Speakers Learning English. 3L: Language, Linguistics, Literature $\circledast$, 23(4), 143-156.

[7] J. M. Li, (2006). Typological markedness and avoidance in Chinese college students' production of English relative clauses. Teaching English in China, (05), 40-46+127.

[8] S. M. Wang, W. U. Ding-Min, (2009). Use of English tenses by Chinese Students from the Perspective of Markedness. Journal of Nanjing University of Aeronautics and Astronautics (Social Sciences), (01), 76-81.

[9] A. G. Mehrdad, M. R. Ahghar, (2015). Markedness and Syllabus Design in SLA. Procedia-Social and Behavioral Sciences, 177, 104-108.

[10] M. Saville-Troike, (2010). Introducing second language acquisition. Cambridge Univ. Press.

[11] X. L. Zhang, (1990). On prepositional phrases serving as the subject - the grammatical functions of prepositional phrases. Journal of Zhejiang Normal University (Social Sciences), (1), 36-42. 